who present with respiratory failure of uncertain origin, even when no other neurological abnormality is present.

We thank Dr M Braithwaite, Brompton Chest Hospital, London, for help with case 1 .

1 Park TS, Hoffman HJ, Hendrick EB, Humphreys RP. Experience with surgical decompression of the Arnold-Chiari malformation in young infants with myelomeningocele. Neurosurgery 1983;13:147-52.

2 Fish DR, Howard RS, Wiles CM, Simon L. Respiratory arrest: a complication of ectopia in adults. F Neurol Neurosurg Psychiatry 1988;51:714-6.

3 Bokinski GE, Hudson LD, Weil JV. Impaired peripheral chemosensitivity and acute respiratory failure in Arnold-Chiari malformation and syringomyelia. N Engl f Med 1973;288:947-8.

4 Balk RA, Hiller FC, Lucas EA, Scrina L, Wison FJ, Wooten V. Sleep apnoea and the Arnold-Chiari malformation. Am Rev Resp Dis 1985;132:929-30.

(Accepted 15 Seplember 1988)

\section{Detection of lupus anticoagulant in patients attending an anticoagulation clinic}

\author{
P Chu, K Pendry, T E Blecher
}

\section{Department of}

Haematology, University

Hospital, Nottingham NG7 2UH

$\mathrm{PChu}, \mathrm{MRCP}$, senior registrar

$\mathrm{K}$ Pendry, MRCP, senior house officer

T E Blecher, FRCP, consultant haematologist

Correspondence to: Dr Chu.
The presence of the lupus anticoagulant is now known to indicate a tendency towards thromboses and recurrent abortions. ${ }^{1}$ In patients with a history of thrombosis identifying the presence of lupus anticoagulant is clinically important as long term anticoagulation treatment should perhaps be considered. We determined the prevalence of lupus anticoagulant in selected patients attending an anticoagulation clinic.

\section{Patients, methods, and results}

About 1300 patients in total attend the anticoagulation clinic at this hospital. The following patients were selected to be screened for lupus anticoagulant: patients of any age with a history of recurrent thrombosis or an episode of thrombosis at a site other than veins of the legs, such as the axillary vein; patients aged less than 40 with a history of venous or arterial thrombosis in the absence of any known predisposing factors, such as the use of contraceptive pills, prolonged immobilisation, malignancy, obesity, or cardiac arrhythmias; and women with a history of both thrombosis and recurrent abortions or unexplained intrauterine death. The

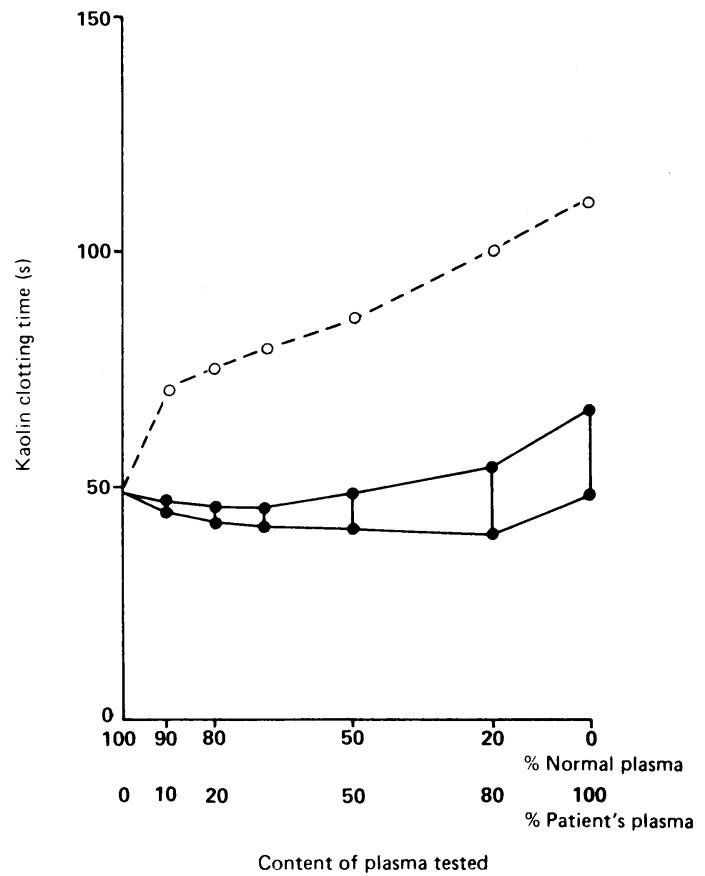

Positive result of testing for lupus anticoagulant ( $\left.\mathrm{O}-\mathrm{-}_{---} \mathrm{O}\right)$, showing convexity on left, and limits of negative results obtained in six unselected patients treated with warfarin $(\bullet-\cdots)$ presence of lupus anticoagulant was detected by measuring the effect of patients' plasma on the kaolin clotting time of normal plasma. ${ }^{2}$ The patients were also screened for anticardiolipin antibodies.

We identified 29 patients who fulfilled the above criteria, comprising 12 men and 17 women with a median age of 36 (range 22-60). Nine of these patients (four men, five women) were found to be positive for lupus anticoagulant (figure) on two separate occasions. The 20 other patients were negative for it. Of the nine patients with lupus anticoagulant, three had a history of arterial thrombosis, of whom one had had two myocardial infarctions. Four had a history of recurrent venous thrombosis, and two had a history of both venous thrombosis and recurrent abortions. Seven were tested for anticardiolipin antibodies and five were found to have raised titres. One patient had coexisting thrombocytopenia, but none had any clinical history or laboratory features suggestive of systemic lupus erythematosus.

\section{Comment}

Our results show that the selection criteria that we used will identify a subpopulation of patients attending an anticoagulation clinic who have a surprisingly high prevalence of lupus anticoagulant $(30 \%)$. This could be of considerable clinical value as the presence of lupus anticoagulant is increasingly appreciated as constituting a risk factor for thrombosis. Possibly such patients should be given prophylactic long term anticoagulation treatment. ${ }^{3}$ In the case of pregnant patients such information would form a rational basis for advice on treatment. We emphasise, however, that our study was targeted at a highly selected group of patients, and the overall prevalence of lupus anticoagulant in unselected patients with thrombosis is as low as $2 \% .{ }^{4}$

In conclusion, we recommend that screening certain selected patients attending anticoagulation clinics will identify several for whom long term anticoagulation treatment might be an advantage.

1 Hughes GRV. Thrombosis, abortion, cerebral disease and the lupus anticoagulant. BrMed f 1983;287:1088-9.

Exner T, Richard KA, Kronenberg H. A sensitive test demonstrating lupus anticoagulant and its behavioural patterns. Br f Haematol 1978;40:143-51.

Williams $\mathrm{H}$, Laurent $R$, Gibson $T$. The lupus coagulant inhibitor and venous thrombosis: a report of four cases. Clin Lab Haematol 1980;2:139-44.

4 Tobelem G, Carion R, Camez A. The lupus anticoagulant and its role in thrombosis. Blood Reviews 1987;1:21-4.

(Accepted 2 August 1988 )

\section{Correction}

Vasoactive and atherogenic effects of cigarette smoking: a study of monozygotic twins discordant for smoking

An editorial error occurred in this paper by Dr R Lassila and others (15 October, $p$ 955). In the third sentence of the third paragraph of the discussion prostaglandin $F_{1 \alpha}$ receptor was substituted for $\alpha_{1}$ adrenoceptor. The sentence should have read: "In humans vasoconstriction mediated by $\alpha_{1}$ adrenoceptor releases urinary prostaglandins in response to infusion with norepinephrine, ${ }^{34}$ and in an animal model stimulation of the sympathetic nerves leads to a significant rapid increase in output of prostacyclin from the mesenteric arterial bed. ${ }^{35}$ " 